\title{
Nonviral gene transfer of hepatocyte growth factor attenuates neurologic injury after spinal cord ischemia in rabbits
}

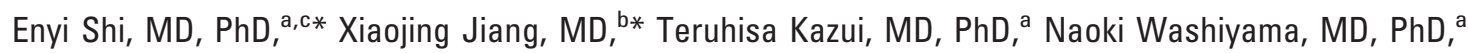
Katsushi Yamashita, MD, PhD, ${ }^{a}$ Hitoshi Terada, MD, PhD, a and Abul Hasan Muhammad Bashar, MBBS, PhD ${ }^{a}$

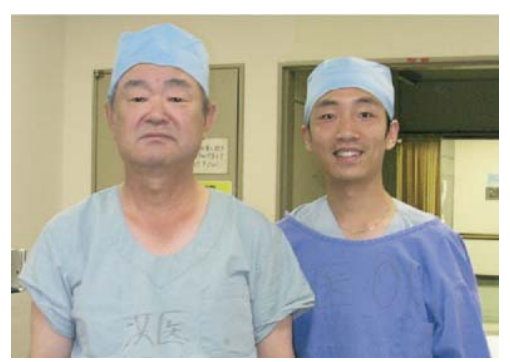

Prof Kazui and Dr Shi (left to right)
From the First Department of Surgery ${ }^{a}$ and the Department of Anesthesiology, Hamamatsu University School of Medicine, Hamamatsu, Japan, and the Department of Cardiac Surgery, ${ }^{c}$ the First Affiliated Hospital, China Medical University, Shenyang, China.

Enyi Shi is supported by Japan Society for the Promotion of Science. This work was supported by Research Grants for JSPS Postdoctoral Fellows (no. 05239).

Received for publication April 24, 2006; revisions received June 11, 2006; accepted for publication June 16, 2006.

Address for reprints: Teruhisa Kazui, MD, $\mathrm{PhD}$, the First Department of Surgery, Hamamatsu University School of Medicine, 1-20-1 Handayama, Hamamatsu 431-3192, Japan (E-mail: tkazui@hama-med.ac.jp).

*Enyi Shi and Xiaojing Jiang contributed equally to this work.

J Thorac Cardiovasc Surg 2006;132:941-7

0022-5223/\$32.00

Copyright (C) 2006 by The American Association for Thoracic Surgery

doi:10.1016/j.jtcvs.2006.06.018
Objective: Paraplegia caused by spinal cord ischemia remains a serious complication after surgical repair of thoracoabdminal aortic aneurysms. Hepatocyte growth factor is a potent angiogenic and neurotrophic factor. We sought to investigate the neuroprotective effect of gene transfer of hepatocyte growth factor on spinal cord ischemia in rabbits.

Methods: Human hepatocyte growth factor expression plasmid was combined with hemagglutinating virus of Japan envelope vector. Hemagglutinating virus of Japan envelope vector containing the hepatocyte growth factor gene was injected intrathecally into the experimental rabbits, whereas control vector or saline was given to the control animals. Five days later, spinal cord ischemia was induced by means of infrarenal aortic occlusion for 30 minutes. Hind-limb motor function was assessed during a 14-day recovery period with Tarlov criteria.

Results: Human hepatocyte growth factor was detected in the cerebrospinal fluid 3 days after gene transfer, and the level peaked on day 5. Compared with the control animals, hepatocyte growth factor gene transfer significantly increased the capillary density in the gray matter and decreased the spinal cord edema. All rabbits pretreated with saline or control vector had hind-limb paraplegia (Tarlov score $=0$ ) 14 days after spinal cord ischemia. However, previous transfection of the hepatocyte growth factor gene remarkably enhanced the Tarlov scores, and 8 of the 9 rabbits showed normal motor function (Tarlov score $=5$ ) after a 14-day recovery period. Histologic examination showed that the intact motor neurons were preserved to a much greater extent in the rabbits transfected with the hepatocyte growth factor gene.

Conclusion: Gene transfer of hepatocyte growth factor attenuates neurologic injury after spinal cord ischemia.

$\mathrm{P}$ araplegia that results from spinal cord ischemia remains a major devastating and unpredictable complication after surgical repair of descending and thoracoabdominal aortic aneurysms. Regardless of the progress with surgical techniques and pharmacologic interventions, this complication still cannot be prevented completely. ${ }^{1,2}$

Therapeutic angiogenesis has been considered to be an effective way to treat ischemic disorders of the central nervous system (CNS). Neurons are highly sensitive to ischemia, and transient ischemia can induce delayed neuronal death, even after recirculation. Therefore the simple effect of stimulation of angiogenesis might not be enough to treat CNS ischemia. An ideal therapeutic strategy to treat ischemic neurologic injury should have both aspects of enhancement of collateral formation and prevention of neuronal death. Recently, it has been demonstrated that hepatocyte growth factor (HGF) functions as a powerful angiogenic factor, ${ }^{3,4}$ as well as a potent neurotrophic factor, ${ }^{5,6}$ although HGF was originally identified from 


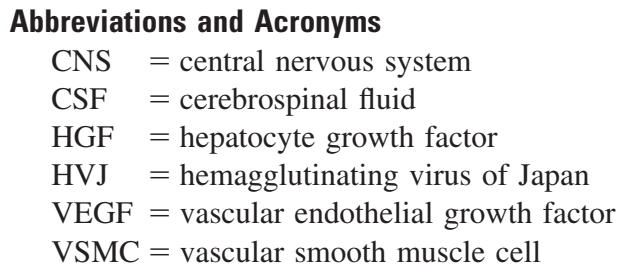

plasma and serum as a molecule that could stimulate DNA synthesis in rat and human hepatocytes. ${ }^{7}$ HGF has been reported to induce versatile neuroprotective effects both in vitro and in vivo, ${ }^{8-13}$ which has led to the hypothesis that HGF can be beneficial in treating neurologic disorders of spinal cord ischemia. The aim of the present study was to determine whether prophylactic gene transfer of human HGF into the subarachnoid space by using hemagglutinating virus of Japan (HVJ) envelope vector can attenuate neurologic injuries of spinal cord ischemia in a wellcharacterized rabbit model.

\section{Materials and Methods}

\section{Construction of Plasmids}

Human HGF cDNA (2.2 kb) was inserted between the EcoRI and NotI sites of the pUC-Sr $\alpha$ expression vector plasmid to produce an HGF expression vector. A pcDNA 3.1(-) plasmid DNA vector with the same structure but not containing HGF cDNA was used as a control vector. ${ }^{11}$

\section{Preparation of HVJ Envelope Vector}

HVJ envelope vector was prepared as described previously. ${ }^{14}$ Briefly, HVJ was purified by means of centrifugation and inactivated by UV irradiation, which abolished the replication of the virus completely but did not affect the cell membrane-fusing capability of the envelope. HVJ envelope (20 AU) was mixed with $200 \mu \mathrm{g}$ of plasmid DNA and $0.3 \%$ Triton-X. After centrifugation, the mixture was washed with $1 \mathrm{~mL}$ of balanced salt solution to remove the detergent and unincorporated DNA. Then the envelope vector was suspended in $400 \mu \mathrm{L}$ of phosphate-buffered saline, and the suspension was stored at $4^{\circ} \mathrm{C}$ until use.

\section{Animal Care and Surgical Procedure}

Japanese white rabbits weighing 1.8 to $2.4 \mathrm{~kg}$ were used in the study. The animal protocol was approved by the Ethics Review Committee for Animal Experimentation of Hamamatsu University School of Medicine and was in accordance with the National Institutes of Health "Guide for the care and use of laboratory animals." Spinal cord ischemia was induced by infrarenal aortic occlusion, according to the method described previously. ${ }^{15}$

\section{In Vivo Gene Transfer and Experimental Protocol}

The intervertebral space between L5 and L6 was punctured with a 16-gauge needle, and polyethylene-10 tubing was inserted through it into the subarachnoid space. The desired position of the catheter was confirmed by means of cautious aspiration of cerebrospinal fluid (CSF). ${ }^{16}$ After removal of $400 \mu \mathrm{L}$ of CSF, saline $(400 \mu \mathrm{L})$, HVJ envelope vector $(400 \mu \mathrm{L})$ containing pcDNA $3.1(-)$, or human HGF plasmid DNA was carefully injected into the saline group $(n=7)$, control vector group $(n=7)$, or HGF group $(n=9)$, respectively. The animals were included in the study only if they had normal hind-limb motor function after intrathecal injection. Five days later, all rabbits were subjected to 30 minutes of spinal cord ischemia.

\section{Measurement of Human HGF Concentration in CSF}

One hundred microliters of CSF was collected before gene transfer and 3,5,12, and 19 days after gene transfer. The concentration of HGF in the CSF was determined by means of enzyme immunoassay with an anti-human HGF antibody (Institute of Immunology, Tokyo, Japan), which reacts only with human HGF but not with rabbit $\mathrm{HGF}^{10,12}$

\section{Neurologic Assessment}

During a 14-day recovery after ischemia, hind-limb motor function was assessed by 2 blinded observers using the modified Tarlov scale $^{17}$ : 0 , no movement; 1 , slight movement; 2 , sit with assistance; 3, sit alone; 4, weak hop; 5, normal hop.

\section{Quantification of Capillary Density}

Additional rabbits ( $\mathrm{n}=5$ for each group) were killed just before spinal cord ischemia to analyze the angiogenic effect of HGF gene transfer in the spinal cord. Alkaline phosphatase staining was used as a specific marker of endothelial cells in paraffin-embedded sections $(10 \mu \mathrm{m}) .{ }^{10}$ The number of microvessels in the ventral gray matter was counted by a blinded investigator. Three individual sections from the lumbar spinal cord (L4-L6) were analyzed.

\section{Evaluation of Spinal Cord Edema After Transient Ischemia}

In a parallel series of experiments ( $n=5$ for each group), spinal cords were collected from rabbits 24 hours after ischemia. Spinal cords were divided into ischemic segments (lumbar spinal cords, L4-L6) and nonischemic segments (thoracic spinal cords, T8-T10). The wet weight was measured quickly, and then the spinal cord was dried in an oven at $110^{\circ} \mathrm{C}$ for 24 hours. The water content was calculated as follows:

$$
\begin{aligned}
\text { Water content }(\%)= & (\text { Wet weight }- \text { Dry weight }) \\
& \times 100 / \text { Wet weight. }{ }^{12}
\end{aligned}
$$

\section{Histologic Study}

All animals of the 3 groups were killed 14 days after the transient ischemia. Paraffin-embedded sections $(4 \mu \mathrm{m})$ of lumbar spinal cords (L4-L6) were stained with hematoxylin and eosin. In cases in which the cytoplasm was diffusely eosinophilic, the large motor neuron cells were considered to be necrotic or dead. When the cells demonstrated basophilic stippling (containing Nissl substance), the motor-neuron cells were considered to be viable or alive. ${ }^{18}$ The intact motor neurons in the ventral gray matter were counted by a 


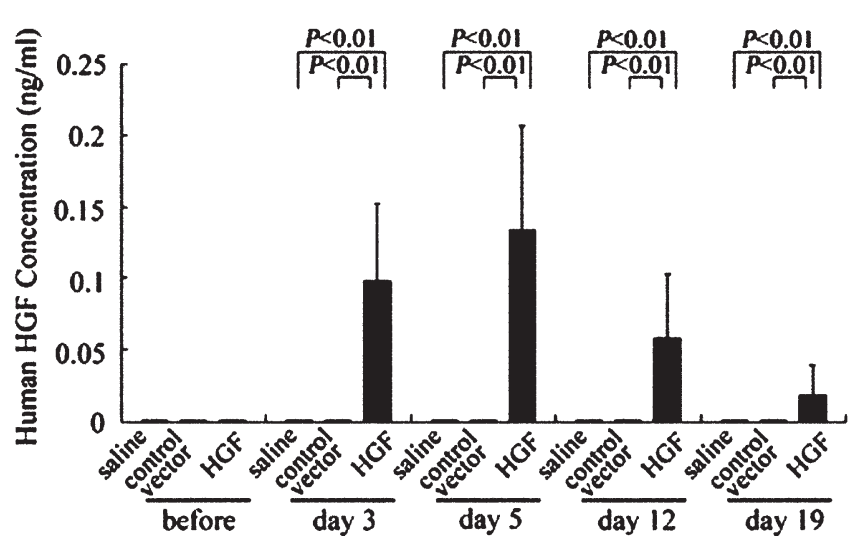

Figure 1. Concentration of human hepatocyte growth factor (HGF) protein in cerebrospinal fluid before transfection and 3 , 5, 12, and 19 days after transfection. Saline, Rabbits pretreated with intrathecal injection of saline; control vector, rabbits transfected with control vector; $H G F$, rabbits transfected with human HGF vector.

blinded investigator in 3 sections for each rabbit, and the results were then averaged.

\section{Statistical Analysis}

Values were expressed as means \pm standard deviation. The KruskalWallis test for nonparametric values and analysis of variance with the subsequent Duncan test for parametric values were used.

\section{Results}

\section{Human HGF Expression}

Human HGF protein was readily detected in the CSF of rabbits transfected with human HGF vector 3 days after transfection but not before transfection (Figure 1). The expression level peaked on day 5 and then dropped off gradually. Human HGF still could be detected 19 days after gene transfection. However, no such expression could be detected in animals that received saline or control vector at any defined time point.

\section{Angiogenesis Induced by HGF Gene Transfer}

The microvessels in the spinal cord of rabbits transfected with the HGF gene showed a more complex pattern than those of rabbits pretreated with saline or control vector 5 days after transfection (Figure 2, A). Consistently, transfection of the HGF gene significantly increased the capillary density in the ventral gray matter compared with that seen in animals pretreated with saline or control vector $(P<.01$, respectively; Figure 2, $B$ ).

\section{Water Content After Spinal Cord Ischemia}

Twenty-four hours after transient infrarenal aortic occlusion, the ischemic spinal cord of the 3 groups contained
$\mathbf{A}$
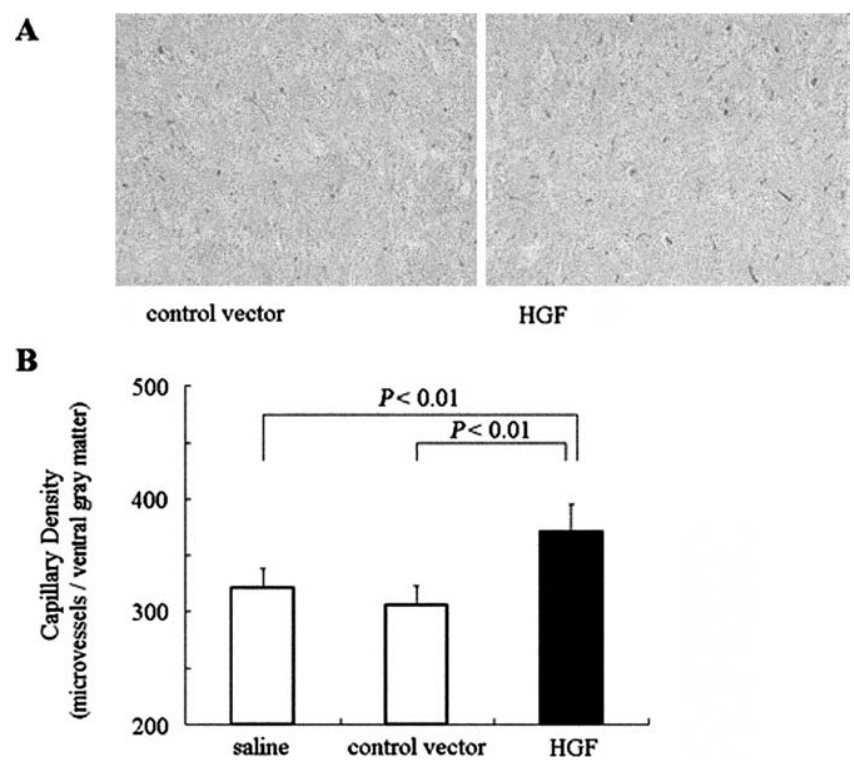

Figure 2. Angiogenic effects of transfection of human hepatocyte growth factor (HGF) gene on the spinal cord 5 days after transfection. A, Representative cross-sections. (Original magnification $100 \times$.) B, Number of vessels in the ventral gray matter of the spinal cord. Saline, Rabbits pretreated with intrathecal injection of saline; control vector, rabbits transfected with control vector; HGF, rabbits transfected with human HGF vector.

more water than the corresponding nonischemic segments (Figure 3). Compared with the rabbits pretreated with saline and control vector, the water content in the ischemic spinal cords of rabbits transfected with human HGF was significantly decreased $(P<.05$, respectively).

\section{Neurologic Assessment}

The individual neurologic scores of the 3 groups before ischemia and 1, 2, 7, and 14 days after ischemia are shown in Figure 4. All rabbits showed normal hind-limb motor function after intrathecal injection and before the induction of ischemia (Tarlov score $=5$ ). A 30-minute period of infrarenal aortic occlusion resulted in severe lowerextremity neurologic deficits in the rabbits pretreated with saline and control vectors, in which all rabbits showed complete paralysis (Tarlov score $=0$ ) after the 14-day observation period. Although evidence of early neurologic injury was found 1 day after ischemia, previous transfection of the HGF gene remarkably enhanced the recovery of motor function, and 8 of the 9 rabbits showed normal motor function 14 days later (compared with the Tarlov scores of the saline and control vector groups, $P<.01$, at each of the 4 time points after ischemia, respectively). 


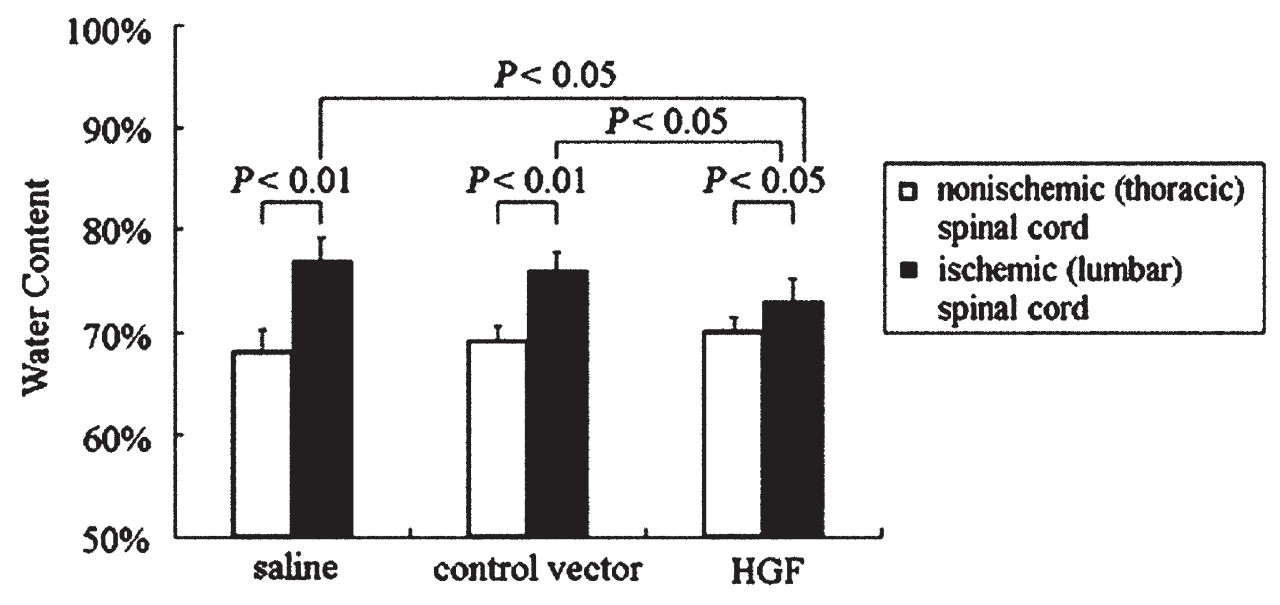

Figure 3. Water content of the spinal cord 24 hours after transient ischemia. Saline, Rabbits pretreated with intrathecal injection of saline; control vector, rabbits transfected with control vector; $H G F$, rabbits transfected with human hepatocyte growth factor (HGF) vector.

\section{Histologic Assessment}

Four rabbits that underwent a sham operation were also enrolled in the histologic study. Representative sections stained with hematoxylin and eosin are shown in Figure 5, A, and the results of counting viable motor neurons are summarized in
Figure $5, B$. In the sham-operated animals the spinal cord was intact, and many large motor neurons were present in the anterior horn. A 30-minute aortic occlusion induced severe neuronal damage in the animals pretreated with saline and control vector 14 days after ischemia, as evidenced by means

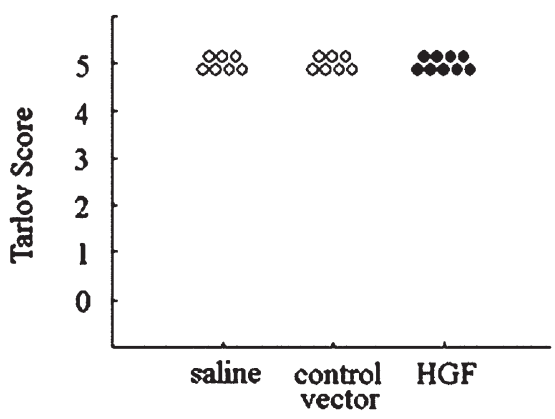

Before ischemia
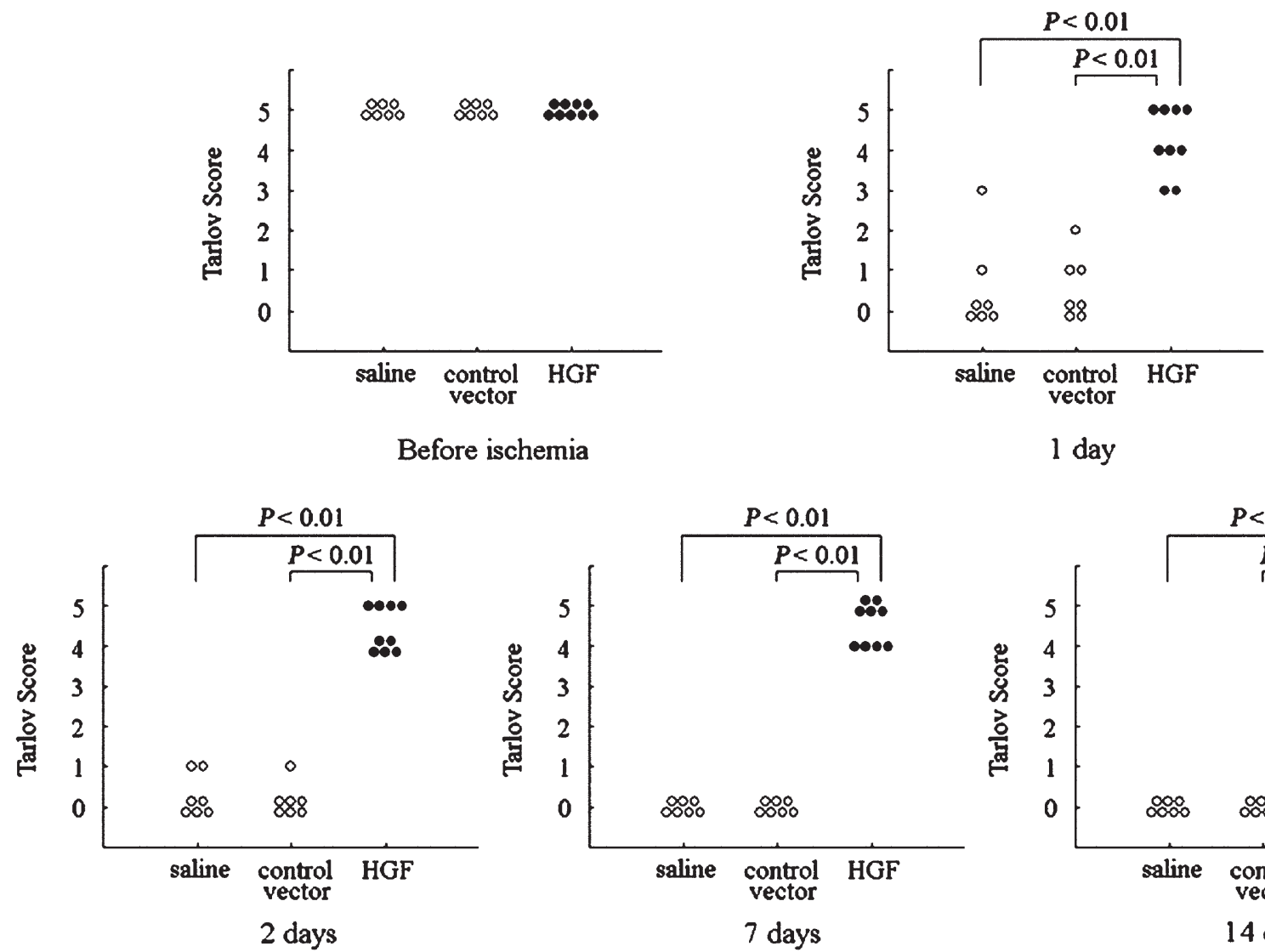

Figure 4. Neurologic function assessed just before spinal cord ischemia and 1, 2, 7, and 14 days after ischemia. Cycles represent individual rabbits. Saline, Rabbits pretreated with intrathecal injection of saline; control vector, rabbits transfected with control vector; HGF, rabbits transfected with human hepatocyte growth factor (HGF) vector. 
$\mathbf{A}$
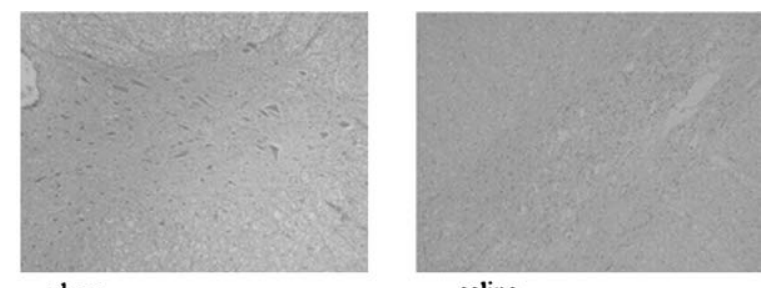

sham

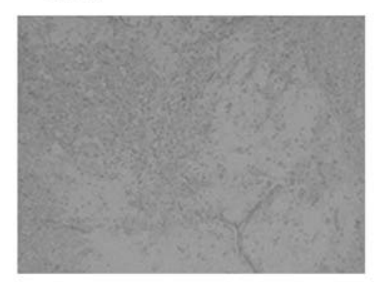

control vector

B

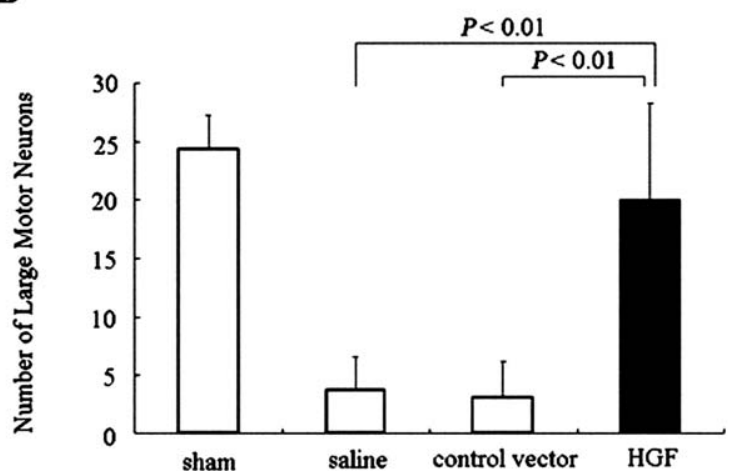

Figure 5. Histologic assessment of the spinal cord 14 days after transient ischemia. A, Representative sections of lumbar spinal cords stained with hematoxylin and eosin. (Original magnification $100 \times$.) HGF, Hepatocyte growth factor. B, Number of large motor neurons in the ventral gray matter. Saline, Rabbits pretreated with intrathecal injection of saline; control vector, rabbits transfected with control vector; HGF, rabbits transfected with human hepatocyte growth factor (HGF) vector.

of vacuolization, frank necrosis, and an almost total loss of the motor neurons. No significant difference in the motor neuron count was found between the saline and control vector groups $(P>.05)$. In contrast, only slight histologic changes were found in the lumbar spinal cords of animals that received HGF gene transfer, and most of the motor neurons remained intact $(P<.01$ versus both the saline and control vector groups, respectively).

\section{Discussion}

Spinal cord ischemia discussed in the present study is a complication of surgical intervention, and the exact time of its occurrence can be known. Therefore precautionary measures to protect the spinal cord are necessary and feasible. We have tried a novel prophylactic strategy to prevent spinal cord injury in the current study, and the data dem- onstrate the following: (1) gene transfer into the spinal cord can be performed successfully by means of intrathecal injection of HVJ envelope vector containing HGF expression plasmid, (2) overexpression of the HGF gene induces angiogenesis in the spinal cord and reduces spinal cord edema after ischemia, and (3) previous transfection of the HGF gene significantly attenuates neurologic deficits caused by spinal cord ischemia.

HGF is a well-known pleiotropic cytokine that exhibits mitogenic and morphogenic activities toward a variety of cells, including endothelial cells. ${ }^{19}$ The mitogenic activity of HGF in endothelial cells was reported to be even more potent than that of vascular endothelial growth factor (VEGF). ${ }^{20}$ Therefore, HGF has been identified as a potential angiogenic factor. In vivo evidences demonstrate that HGF stimulates angiogenesis with increase of blood flow in various tissues, such as myocardium, ${ }^{21}$ skeletal muscle, ${ }^{17}$ and brain. ${ }^{10,12}$ Moreover, HGF also plays a role as a neurotrophic and survival factor to maintain the physiologic structure and function of the nervous system. Both HGF and c-Met, an HGF receptor of membrane-spanning tyrosine kinase, are expressed in various regions of the brain ${ }^{5}$ and peripheral neurons. ${ }^{22}$ Functional coupling between HGF and c-Met enhances the survival of hippocampal neurons in primary culture and induces neurite outgrowth in neuronal development in vitro. ${ }^{23}$ Sensory and sympathetic neurons and their precursors respond to HGF with increased differentiation, survival, and axonal outgrowth. ${ }^{24}$ HGF is expressed in the brain in the early phase after cerebral ischemia $^{25}$ and induces a neuroprotective effect against postischemic delayed neuronal death in the hippocampus. ${ }^{26}$ In cerebral artery occlusion models HGF has been reported to induce therapeutic angiogenesis, improve blood flow, reduce the infarct volume, and attenuate neurologic injuries, ${ }^{10,12,13}$ which demonstrates that HGF possesses a potential therapeutic value for CNS ischemia. It is plausible that HGF secreted from transfected cells induces the powerful neuroprotective effects observed in the current study through its angiogenic and neurotrophic activities.

However, the short serum half-life of the recombinant protein limits the therapeutic value of HGF. Gene transfer appears to have advantages over the administration of singleor multiple-bolus doses of a recombinant protein because it can achieve an optimally high local concentration of protein within the nervous system. ${ }^{10-12}$ In the study by Yoshimura and colleagues, ${ }^{10}$ gene transfer of HGF markedly increased the cerebral blood flow in the ischemic brain, whereas single injection of recombinant HGF failed to do so. For gene transfer to the spinal cord, a nonviral HVJ envelope-mediated method was used in the current study. Although viral vectors are always used to transfer gene into nervous system for their high transfection efficiency, these vectors are potentially hazardous because of cointroduction of genetic elements 
from parent viruses, leaky expression of viral genes, immunogenicity, and changes in the host genome. ${ }^{27}$ Nonviral vectors are less toxic and less immunogenic. HVJ envelope is a purified vesicle prepared from HVJ, the replication activity and infectivity of which have been completely inhibited, whereas the activities of the 2 envelope proteins (hemagglutinating neuroaminidase and fusion protein) are maintained almost at the same levels as those of live HVJ. This vector has been used to transfer gene into various tissues successfully, including nervous system tissue. ${ }^{12,14}$ Another difficulty for gene transfer to the spinal cord is the presence of the blood-brain barrier, which makes the spinal cord relatively inaccessible to circulating proteins and peptides. Intrathecal injection through lumbar puncture might be a feasible method to overcome this limitation. Our previous study shows that lumbar puncture can be readily performed without severe invasion. ${ }^{16}$ In the present study the human HGF gene was transferred into rabbit spinal cords by means of intrathecal injection. Secretion of HGF from the transfected cells was still detected in the CSF more than 2 weeks after transfection. On the other hand, the blood-brain barrier might also ensure that other organs except CNS are not transfected when gene transfer is performed through intrathecal injection.

VEGF, another important angiogenic factor, also has neuroprotective effects. However, administration of recombinant VEGF to the ischemic brain has been reported to increase cerebral edema, which was provoked in part by enhanced cerebrovascular permeability. ${ }^{28}$ Similarly, lowerlimb edema was reported as a side effect after gene transfer of VEGF into the ischemic limb. ${ }^{29}$ In contrast to these findings, gene transfer of HGF did not augment spinal cord edema in the current study. Indeed, the water content of the ischemic spinal cord was decreased after transfection of the HGF gene. Consistent with our data, overexpression of HGF did not exacerbate cerebral edema and destruction of the blood-brain barrier in the ischemic brain. ${ }^{12}$ The difference in effects of HGF and VEGF on vascular smooth muscle cells (VSMCs) might be the explanation for the divergent edema formation between HGF and VEGF. HGF stimulates the migration of VSMCs without their multiplication, ${ }^{20}$ whereas VEGF has no effect on either the migration or the proliferation of VSMCs because of the lack of VEGF receptors on VSMCs. ${ }^{30}$ Thus angiogenesis induced by VEGF is featured as a delay in the maturation of blood vessels. However, because HGF simultaneously stimulates the migration of both endothelial cells and VSMCs, the blood vessels might mature in a well-coordinated way at an earlier time, thereby avoiding the release of blood-derived cells into the extracellular space. ${ }^{30}$ To this point, HGF might be better to treat CNS ischemia.

In conclusion, our study demonstrates for the first time that intrathecal injection of nonviral HVJ envelope-based vector is efficient in transferring the gene of interest into the spinal cord and that prophylactic gene transfer of HGF induces powerful neuroprotective effects against spinal cord ischemia. Our observations expand the understanding of the neuroprotective properties of HGF. Although the current data are not advanced enough for human gene therapy, the proofs still suggest that gene transfer of HGF might be a novel therapeutic strategy to prevent neurologic injury after thoracic aneurysm surgery.

We thank AnGes MG Inc, Osaka, Japan, for providing the naked plasmid encoding HGF.

\section{References}

1. Svensson LG, Crawford ES, Hess KR, Coselli JS, Safi H. Experience with 1509 patients undergoing thoracoabdominal aortic operations. J Vasc Surg. 1993;17:357-70.

2. Coselli JS, LeMaire SA, Miller CC 3rd, Schmittling ZC, Koksoy C, Pagan J, et al. Mortality and paraplegia after thoracoabdominal aortic aneurysm repair: a risk factor analysis. Ann Thorac Surg. 2000;69: 409-14.

3. Aoki M, Morishita R, Taniyama Y, Kida I, Moriguchi A, Matsumoto $\mathrm{K}$, et al. Angiogenesis induced by hepatocyte growth factor in noninfarcted myocardium and infarcted myocardium: up-regulation of essential transcription factor for angiogenesis, ets. Gene Ther. 2000; 7:417-27.

4. Koike H, Morishita R, Iguchi S, Aoki M, Matsumoto K, Nakamura T, et al. Enhanced angiogenesis and improvement of neuropathy by cotransfection of human hepatocyte growth factor and prostacyclin synthase gene. FASEB J. 2003;17:779-81.

5. Honda S, Kagoshima M, Wanaka A, Tohyama M, Matsumoto K, Nakamura T. Localization and functional coupling of HGF and c-Met/ HGF receptor in rat brain: implication as neurotrophic factor. Brain Res Mol Brain Res. 1995;32:197-210.

6. Korhonen L, Sjoholm U, Takei N, Kern MA, Schirmacher P, Castren E, et al. Expression of c-Met in developing rat hippocampus: evidence for HGF as a neurotrophic factor for calbindin D-expressing neurons. Eur J Neurosci. 2000;12:3453-61.

7. Nakamura T, Nawa K, Ichikawa A, Kaise N, Nishimoto T. Purification and subunit structure of hepatocyte growth factor from rat platelets. FEBS Lett. 1987;224:311-6.

8. Hayashi K, Morishita R, Nakagami H, Yoshimura S, Hara A, Matsumoto $\mathrm{K}$, et al. Gene therapy for preventing neuronal death using hepatocyte growth factor: in vivo gene transfer of HGF to subarachnoid space prevents delayed neuronal death in gerbil hippocampal CA1 neurons. Gene Ther. 2001;8:1167-73.

9. Zhang L, Himi T, Morita I, Murota S. Hepatocyte growth factor protects cultured rat cerebellar granule neurons from apoptosis via the phosphatidylinositol-3 kinase/Akt pathway. J Neurosci Res. 2000;59: 489-96.

10. Yoshimura S, Morishita R, Hayashi K, Kokuzawa J, Aoki M, Matsumoto K, et al. Gene transfer of hepatocyte growth factor to subarachnoid space in cerebral hypoperfusion model. Hypertension. 2002;39: 1028-34.

11. Kato N, Nemoto K, Nakanishi K, Morishita R, Kaneda Y, Uenoyama $\mathrm{M}$, et al. Nonviral HVJ (hemagglutinating virus of Japan) liposomemediated retrograde gene transfer of human hepatocyte growth factor into rat nervous system promotes functional and histological recovery of the crushed nerve. Neurosci Res. 2005;52:299-310.

12. Shimamura M, Sato N, Oshima K, Aoki M, Kurinami H, Waguri S, et al. Novel therapeutic strategy to treat brain ischemia: overexpression of hepatocyte growth factor gene reduced ischemic injury without cerebral edema in rat model. Circulation. 2004;109:424-31.

13. Tsuzuki N, Miyazawa T, Matsumoto K, Nakamura T, Shima K Hepatocyte growth factor reduces the infarct volume after transient focal cerebral ischemia in rats. Neurol Res. 2001;23:417-24. 
14. Kaneda Y, Nakajima T, Nishikawa T, Yamamoto S, Ikegami H, Suzuki N, et al. Hemagglutinating virus of Japan (HVJ) envelope vector as a versatile gene delivery system. Mol Ther. 2002;6:219-26.

15. Shi E, Kazui T, Jiang X, Washiyama N, Suzuki K, Yamashita K, et al. NS-7, a novel $\mathrm{Na}+/ \mathrm{Ca} 2+$ channel blocker, prevents neurologic injury after spinal cord ischemia in rabbits. J Thorac Cardiovasc Surg. 2005;129:364-71.

16. Shi E, Kazui T, Jiang X, Washiyama N, Yamashita K, Terada H, et al. Intrathecal injection of bone marrow stromal cells attenuates neurologic injury after spinal cord ischemia. Ann Thorac Surg. 2006;81: 2227-34.

17. Tarlov IM. Acute spinal cord compression paralysis. J Neurosurg. 1972;36:10-20.

18. Mutch WA, Graham MR, Halliday WC, Thiessen DB, Girling LG. Use of neuroanesthesia adjuncts (hyperventilation and mannitol administration) improves neurological outcome after thoracic aortic cross-clamping in dogs. Stroke. 1993;24:1204-10.

19. Nakamura T, Nishizawa T, Hagiya M, Seki T, Shimonishi M, Sugimura A, et al. Molecular cloning and expression of human hepatocyte growth factor. Nature. 1989;342:440-3.

20. Nakamura Y, Morishita R, Nakamura S, Aoki M, Moriguchi A, Matsumoto K, et al. A vascular modulator, hepatocyte growth factor, is associated with systolic pressure. Hypertension. 1996;28:409-13.

21. Jayasankar V, Woo YJ, Bish LT, Pirolli TJ, Chatterjee S, Berry MF, et al. Gene transfer of hepatocyte growth factor attenuates postinfarction heart failure. Circulation. 2003;108(suppl):II230-6.

22. Hashimoto N, Yamanaka H, Fukuoka T, Dai Y, Obata K, Mashimo $\mathrm{T}$, et al. Expression of $\mathrm{HGF}$ and cMet in the peripheral nervous system of adult rats following sciatic nerve injury. Neuroreport. 2001; 12:1403-7.

23. Jung W, Castren E, Odenthal M, Vande Woude GF, Ishii T, Dienes $\mathrm{HP}$, et al. Expression and functional interaction of hepatocyte growth factor-scatter factor and its receptor c-met in mammalian brain. $J$ Cell Biol. 1994;126:485-94.

24. Maina F, Klein R. Hepatocyte growth factor, a versatile signal for developing neurons. Nat Neurosci. 1999;2:213-7.

25. Hayashi T, Abe K, Sakurai M, Itoyama Y. Inductions of hepatocyte growth factor and its activator in rat brain with permanent middle cerebral artery occlusion. Brain Res. 1998;799:311-6.

26. Miyazawa T, Matsumoto K, Ohmichi H, Katoh H, Yamashima T, Nakamura T. Protection of hippocampal neurons from ischemiainduced delayed neuronal death by hepatocyte growth factor: a novel neurotrophic factor. J Cereb Blood Flow Metab. 1998;18:345-8.

27. Mulligan RC. The basic science of gene therapy. Science. 1993;260: 926-32.

28. Zhang ZG, Zhang L, Jiang Q, Zhang R, Davies K, Powers C, et al. VEGF enhances angiogenesis and promotes blood-brain barrier leakage in the ischemic brain. J Clin Invest. 2000;106:829-38.

29. Baumgartner I, Rauh G, Pieczek A, Wuensch D, Magner M, Kearney $\mathrm{M}$, et al. Lower-extremity edema associated with gene transfer of naked DNA encoding vascular endothelial growth factor. Ann Intern Med. 2000;132:880-4.

30. Morishita R, Aoki M, Hashiya N, Yamasaki K, Kurinami H, Shimizu $\mathrm{S}$, et al. Therapeutic angiogenesis using hepatocyte growth factor (HGF). Curr Gene Ther. 2004;4:199-206. 